\title{
Analysis of noise inside bus of hybrid bus vehicles
}

\author{
Lukasz Konieczny ${ }^{1}$, Rafal Burdzik ${ }^{2}$, Robert Jaworski ${ }^{3}$, Sławomir Wierzbicki ${ }^{4}$ \\ ${ }^{1,2}$ Silesian University of Technology, Faculty of Transport, Gliwice, Poland \\ ${ }^{3}$ Vehicle Inspection Office, Vehicle Appraiser Certified by the Ministry of Infrastructure and Construction, \\ Gliwice, Poland \\ ${ }^{4}$ University of Warmia and Mazury in Olsztyn, Faculty of Technical Sciences, Olsztyn, Poland \\ ${ }^{1}$ Corresponding author \\ E-mail: ${ }^{1}$ lukasz.konieczny@polsl.pl, ${ }^{2}$ rafal.burdzik@polsl.pl, ${ }^{3}$ jaworski.rzeczoznawca@gmail.com, \\ 4slawekw@uwm.edu.pl
}

Received 6 September 2018; accepted 17 September 2018 DOI https://doi.org/10.21595/vp.2018.20229

Check for updates

Copyright (C) 2018 Lukasz Konieczny, et al. This is an open access article distributed under the Creative Commons Attribution License, which permits unrestricted use, distribution, and reproduction in any medium, provided the original work is properly cited.

\begin{abstract}
The article presents the results of noise measurements during a control passage recorded in the interior of a bus with a serial hybrid drive. The noise was recorded in a continuous mode, and the course was adjusted for the pressure level and spectrogram in the field of time and frequency.
\end{abstract}

Keywords: bus noise, diagnostics of car.

\section{Introduction}

The tests were conducted for a city bus with a serial hybrid system in the following configuration: $\mathrm{CNG}$ engine-electric generator-energy recuperation system-central electric drive motor. The research was aimed at addressing the feelings of passengers. The noise related to the operation of a CNG-powered engine causes a burdensome impression of monotone noise which, when prolonged exposure, is annoying, thus impairing the comfort of traveling. An additional negative sound effect is the noise associated with the operation of the electric drive motor on the wheels of the drive axle, generating unpleasant sounds received as a "squeak". The scope of the tests included continuous recording of noise inside the vehicle during the check-up allowing detailed analyses including frequency analysis of the structure of registered noise.

\section{Description of the research procedure}

The tests were carried out in accordance with the reference methodology for measuring noise levels described by the standards: PN-81/N-01306, PN-N-01307:1994, PN-90/S-04052, $\mathrm{PN}-92 / \mathrm{S}-04051$. The guidelines specified in the standards were used in the tests. The test consisted in measuring the noise level in $\mathrm{dB}(\mathrm{A})$ inside the vehicle at specific measuring points during the bus passage. Measurements of noise level in $\mathrm{dB}(\mathrm{A})$ were carried out using the sound level meter on the correction curve A and the dynamic characteristic F (fast). Immediately before and after the measurements the meter was calibrated using a suitable calibrator. The results were referred to the permissible noise level inside vehicles (lorries and city buses - the permissible noise level $\mathrm{dB}(\mathrm{A})$ is $82 \mathrm{~dB})$.

\section{Description of the places of measurement and the method of carrying out the measurements.}

The location of the measurement point was determined due to the adopted research goal, which is, inter alia, the determination of a "hybrid" construction solution powered by CNG for the emission of noise inside the vehicle and the environment. The selected measuring point was located in the rear of the vehicle near the engine compartment. The microphone was placed at a height of $1600 \mathrm{~mm}$ above the floor surface at a distance of $500 \mathrm{~mm}$ from the bulkhead wall of the engine compartment towards the bonnet of the engine (Fig. 1). 

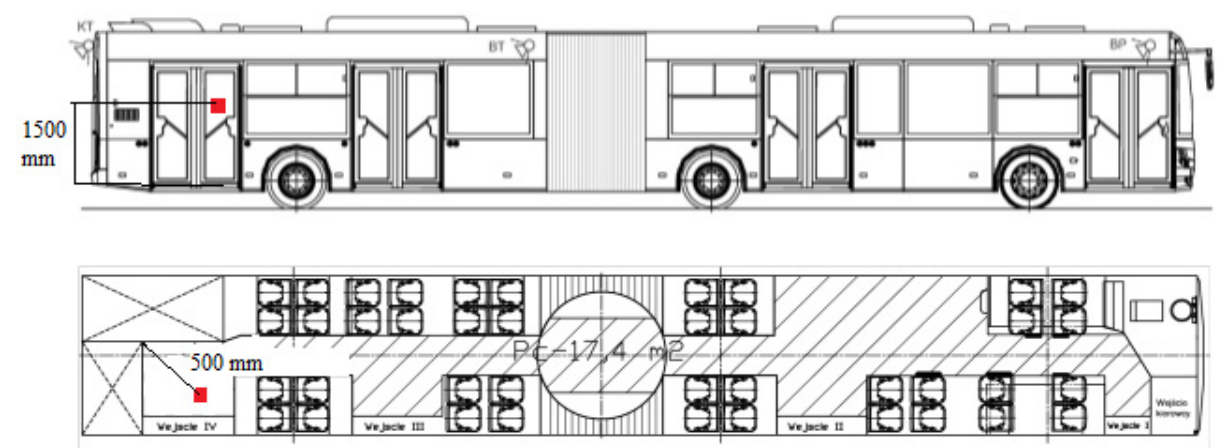

Fig. 1. Location of the measuring point

\section{Characteristics of the measurement set used in the research}

The measuring set used in the tests meets the requirements for integrating or integrating-averaging meters. SON-50 is an integral sound level class 1 accuracy meter that measures transient, fixed and pulsed signals. It is mainly used to measure the quantities that determine the worker's exposure to noise at the workplace (in accordance with current standards), environmental monitoring, and, thanks to the possibility of adding external octave or infrasound filters, can be used for diagnostic tests of machines and devices. The meter has two independent measuring paths: the effective value, for measurement: Leq, Lmx, Lmn and the second, for the measurement of the peak value. Thanks to this, it is possible, for example, to measure the effective value on the A-characteristic and the peak value using the $\mathrm{C}$-characteristic simultaneously. This device also measures the level of exposure to noise related to the set working time.

During the tests, continuous recording of acoustic pressure was carried out. The output analogue signal from the Son-50 sound level meter was recorded on a portable computer (Labview software) using an analogue-digital card. The sampling frequency was lowered to the $25 \mathrm{kHz}$ band. This measuring card has a modular construction and consists of two parts: a charge amplifier (measuring amplifier) and a "frame" with space for this amplifier. The card works in USB High Performance mode with the measurement signal conditioning, has 4 channels, 24-bit resolution, maximum sampling frequency of $50 \mathrm{ks} / \mathrm{s}$, maximum input range $\pm 10 \mathrm{~V}$ and synchronous sampling.

Before and after the measurements, the Son 50 sound level meter was calibrated. The calibration results before and after the measurements were equal to: $94.1 \mathrm{~dB}$.
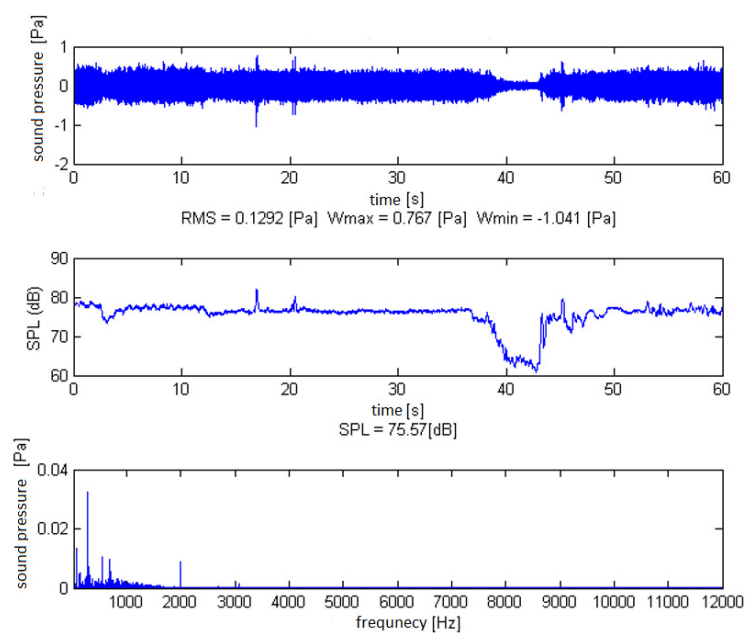

Fig. 2. Time course of registered sound pressure $[\mathrm{Pa}]$, course of sound pressure levels in $[\mathrm{dB}]$ and FFT spectrum-control passage (time 0-60s) 


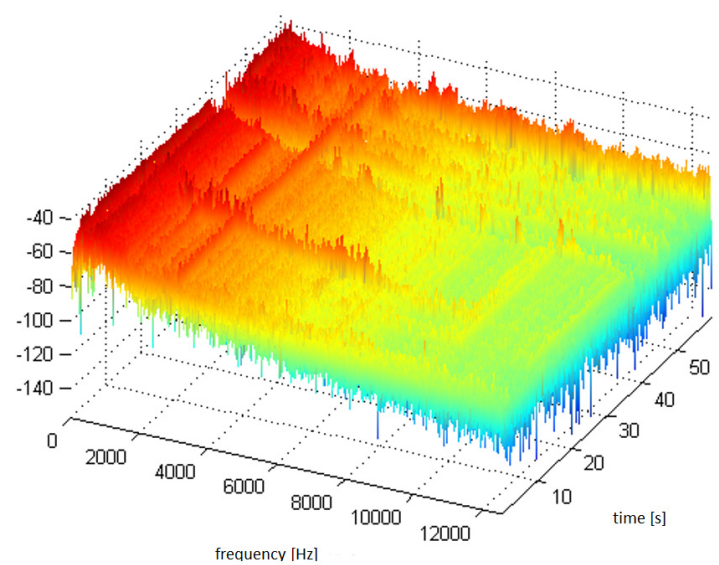

Fig. 3. Spectrogram showing the time-frequency structure of the registered sound pressure signal-control passage (0-1 min)

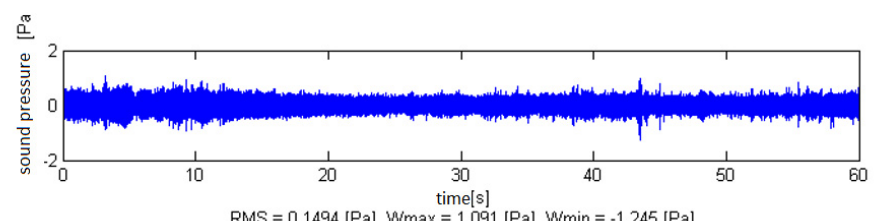

RMS $=0.1494[\mathrm{~Pa}] W_{\max }=1.091[\mathrm{~Pa}] \mathrm{Wmin}_{\min }=-1.245[\mathrm{~Pa}]$
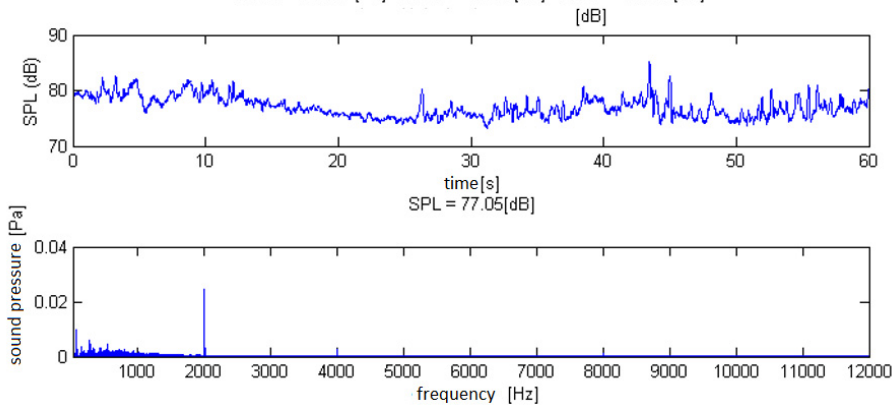

Fig. 4. Time course of registered sound pressure $[\mathrm{Pa}]$, course of values of sound pressure levels in $[\mathrm{dB}]$ and spectrum FFT-control passage (6-7min) - "squeaks" related to the operation of electric drive motors of drive wheels

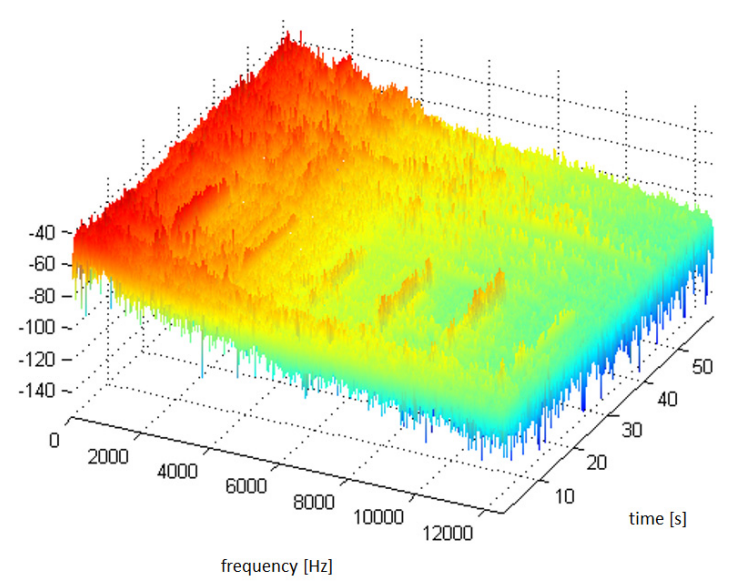

Fig. 5. Spectrum showing the time-frequency structure of the registered sound pressure signal-control passage (6-7 $\mathrm{min})$ - "squeaks" related to the operation of electric drive wheel motors 


\section{Obtained results of research}

After taking measurements registered in the meter's memory, the results were transferred to the computer and saved in the source form. The source form of the obtained measurement results is included in the attachment of this study. The next step was to analyse the acoustic signal, in particular to perform analyses in particular in the aspect of the frequency structure of the acoustic signal. As a result of continuous noise recording at the measuring point during the drive, the spectra of the acoustic signal in time and frequency were determined.

\section{Conclusions}

The obtained sound pressure level results in $[\mathrm{dB}]$ during the control passage do not exceed the permissible values specified in the standard regarding noise inside the vehicle. As already stated, the sound pressure level itself is within the standard (below $82[\mathrm{~dB}]$ ), however, the character of the hybrid vehicle in which fixed speed values have been assumed $(850,1200,1600$ revolutions/min) of the $\mathrm{CNG}$ engine operation, causes troublesome an impression of monotonous noise. An additional negative sound effect is the noise associated with the operation of the electric drive motor on the wheels of the drive axle, generating unpleasant sounds received as a "squeak". The analysis of the frequency structure of registered noise confirms the components in the higher frequency ranges related to the operation of electric drive motors.

Measurements while driving were carried out without distinguishing the type of road and surface as well as the condition of the environment in which the control journeys were carried out (various traffic volumes of motor vehicles, etc.). The results obtained concern the average bus conditions. Nevertheless, the results allow an overall assessment of the noise level inside the hybrid bus while driving.

Summing up the acoustic comfort for traveling vehicles, this type of hybrid is unsatisfactory, and the longer journeys and nature of the noise generated by the vehicle is unpleasant and troublesome.

\section{References}

[1] Balamurugan L., Jancirani J., Eltantawie M. A. Generalized magnetorheological (mr) damper model and its application in semi-active control of vehicle suspension system. International Journal of Automotive Technology, Vol. 15, Issue 3, 2014, p. 419-427.

[2] Burdzik R., Konieczny L., Adamczyk B. Automatic control systems and control of vibrations in vehicles car. Communications in Computer and Information Science, Vol. 471, 2014, p. 1865-929.

[3] Burdzik R., Konieczny L., Lazarz B. Influence of damping characteristics changes on vehicles vibration research. 19th International Congress on Sound and Vibration, Vilnius, Lithuania, 2012.

[4] Burdzik R., Konieczny L. Application of vibroacoustic methods for monitoring and control of comfort and safety of passenger cars. Mechatronic Systems, Mechanics and Materials II. Selected, Peer Reviewed Papers from the Symposium on Mechatronics Systems, Mechanics and Materials 2013, 2014, p. 20-25.

[5] Burdzik R., Konieczny L. New Methods for Identification of Technical Condition of Vehicle Suspension in Term of Driving Safety. Some Actual Issues of Traffic and Vehicle Safety. Monograph, Faculty of Transport, Silesian University of Technology, 2013, p. 83-104.

[6] Cao D. P., Rakheja S., Su C. Y. Roll plane analysis of interconnected hydro-pneumatic suspension struts. Proceedings of the ASME Design Engineering Division, 2005, p. 133-142.

[7] Dixon J. C. The Shock Absorber Handbook. Society of Automotive Engineers Inc., Warrendale, PA, 1999.

[8] Gillespie T. D. Fundamentals of Vehicle Dynamics. SAE International, 1992.

[9] Giliomee C. L. Analysis of a Four State Switchable Hydro-Pneumatic Spring and Damper System. University of Pretoria, 2005.

[10] Konieczny L. Determination of the damping characteristics of hydropneumatic strut taking into account the chosen parameters. Scientific Journal of Silesian University of Technology, Series Transport, Vol. 69, 2010, p. 85-89. 
[11] Konieczny L., Burdzik R., Folęga P., Wieczorek A. N. Determination of the damping characteristics of hydro pneumatic suspension strut. Journal of Measurement in Engineering, Vol. 1, Issue 3, 2013, p. $155-158$.

[12] Konieczny $\mathbf{\ell}$. The statistical analysis of damping parameters of hydraulic shock absorbers. Diagnostic, Vol. 15, Issue 1, 2014, p. 49-52.

[13] Konieczny L., Burdzik R., Warczek J. Determinations of shock absorber dumping characteristics taking stroke value into consideration account. Diagnostyka, Vol. 3, 2010, p. 51-54.

[14] Konieczny L., Burdzik R. Comparison of characteristics of the components used in mechanical and non-conventional automotive suspensions. Trans Tech Publications, Vol. 210, 2014, p. 26-31.

[15] Konieczny Ł., Warczek J., Młyńczak J., Zawisza M. Free vibration method for technical condition assessment of automotive shock absorbers. Diagnostic, Vol. 18, Issue 3, 2017, p. 47-53.

[16] Konieczny $\mathbf{L}$. Analysis of simplifications applied in vibration damping modelling for a passive car shock absorber. Shock and Vibration, Vol. 2016, 2016, p. 6182847.

[17] Lanzendoerfer J. Reaserch of Passenger Cars. WKit, Warszawa, 1997.

[18] Reński A. Car Building: Suspension, Handling and Steering Subsystems. Oficyna Wydawnicza Politechniki Warszawskiej, Warszawa, 2004.

[19] Warczek J., Burdzik R., Peruń G. The method for identification of damping coefficient of the trucks suspension. Key Engineering Materials, Vol. 588, 2014, p. 281-289.

[20] Snamina J., Kowal J., Orkisz P. Active suspension based on low dynamic stiffness. Acta Physica Polonica A, Vol. 123, Issue 6, 2013, p. 1118-1122.

[21] Ho C., Lang Z. Q., Sapinski B. Vibration isolation using nonlinear damping implemented by a feedback-controlled MR damper. Smart Materials and Structures, Vol. 22, Issue 10, 2013, p. 105010. 